\title{
REVIEW
}

\section{Bench-to-bedside review: Rapid molecular diagnostics for bloodstream infection - a new frontier?}

\author{
Arash Afshari'1,2, Jacques Schrenzel ${ }^{3}$, Margareta leven ${ }^{4}$ and Stephan Harbarth ${ }^{1 *}$
}

\begin{abstract}
Among critically ill patients, the diagnosis of bloodstream infection poses a major challenge. Current standard bacterial identification based on blood culture platforms is intrinsically time-consuming and slow. The continuous evolvement of molecular techniques has the potential of providing a faster, more sensitive and direct identification of causative pathogens without prior need for cultivation. This may ultimately impact clinical decision-making and antimicrobial treatment. This review summarises the currently available technologies, their strengths and limitations and the obstacles that have to be overcome in order to develop a satisfactory bedside point-of-care diagnostic tool for detection of bloodstream infection.
\end{abstract}

\section{Introduction}

Bloodstream infections (BSIs) are associated with adverse clinical and health-economic outcomes $[1,2]$. Thirty to forty percent of all cases of severe sepsis and septic shock are culture-proven BSIs, for which there is a rapid decline in survival rates in cases where inadequate antimicrobial therapy is administered within the first 24 hours [3,4]. As a consequence, clinicians often resort to empirical broadspectrum antimicrobial therapy favoring the selection and spread of resistant pathogens (i.e., extended spectrum $\beta$-lactamase producing organisms) [5], increased invasive fungal infections [6,7], rising consumption of more expensive third-line drugs (e.g. tigecycline, daptomycine) [8] and drug toxicity issues (e.g. colistin) $[9,10]$.

Rapid detection of BSIs with determination of antibiotic susceptibility can alter current practices in

\footnotetext{
*Correspondence: stephan.harbarth@hcuge.ch

IInfection Control Program, Geneva University Hospitals and Medical School,

4, rue Gabrielle-Perret-Gentil, CH-1211 Geneva 14, Switzerland

Full list of author information is available at the end of the article
}

infection control, therapeutic management, and clinical decision-making and ultimately reduce over-prescription of antimicrobials and associated adverse outcomes $[11,12]$. This article will present recent technological developments, discuss the shortcomings and advantages of culture-based and molecular diagnostics and describe the requirements for an ideal rapid diagnostic system.

\section{Definitions}

Primary BSI refers to intravascular catheter-related BSI and BSI without an identifiable focus of infection while secondary BSI refers to patients infected by microorganisms originating from another site [13]. The definition of BSI poses certain diagnostic challenges as it coincides with conditions such as transient, intermittent and continuous low-grade bacteraemia. Transient bacteraemia, lasting from minutes to hours, can occur during procedures involving anatomic sites colonized by normal microbial flora (for example, tooth brushing, colonoscopy, dental extractions) or after manipulation of localized skin infections (for example, furuncles). Intermittent bacteraemia, typically associated with closed-space or focal infections (for example, abscesses, pneumonia, osteomyelitis), is characterized by recurrent episodes of bacteraemia because of cyclical clearance and recurrence of the same pathogen. Continuous low-grade bacteraemia is commonly associated with an intravascular focus of infection such as infective endocarditis or vascular-graft infections $[14,15]$. These definitions pose interpretational challenges and should always be put in the context of the clinical presentation as the presence of microorganisms in the bloodstream may merely represent a route of transportation rather than evidence of true BSI. This could occur not only in cases of transient bacteraemia but also when the source of infection is outside the bloodstream.

\section{Blood culture-based detection of bloodstream infections}

Blood cultures are still considered the gold standard of BSI diagnosis, retrieving viable microorganisms to 
determine the species and their antimicrobial susceptibility. Blood cultures are capable of detecting as low as 1 colony-forming unit (CFU) of bacteria or fungi/yeasts per $10 \mathrm{ml}$ blood. However, cultures require incubation times of up to 96 hours, can only detect cultivable microorganisms and have low sensitivity for slow growing, intracellular and fastidious microorganisms and in patients pre-treated with antimicrobials [16]. The positive predictive value of cultures is estimated to be above $95 \%$ but in BSI the overall positivity may be as low as 30 to $40 \%$ despite proper implementation of standard procedures, adequate blood volume collection and substantial clinical suspicion of BSI [16-18].

Collection of two to three blood culture sets per suspected BSI episode with 20 to $30 \mathrm{ml}$ of blood per set (an aerobic and anaerobic bottle) in adults is advised as more sets and higher volumes of blood correspond with a higher detection rate [19]; however, extracting such volumes of blood is not feasible in children and neonates. Furthermore, $50 \%$ of blood cultures may have inadequate volumes of blood, which may ultimately reduce the overall sensitivity of blood cultures [20]. In case of clinically significant bacteraemia, the number of recoverable bacteria in blood of adults is reported to be in the range of 1 to $30 \mathrm{CFU} / \mathrm{ml}$, while it may exceed $100 \mathrm{CFU} /$ $\mathrm{ml}$ in children [21].

Detection time has been significantly reduced by recent advances, including the development of new liquid media and growth supplements, the development of adsorbing agents to neutralize growth inhibitors, metabolic products and remnant antibiotics, the introduction of fully automated instruments with continuous monitoring of growth based on analysis of the proportional release of $\mathrm{CO}_{2}$ using fluorescent or colorimetric sensors, and the co-application of new molecular technologies [22]. Nevertheless, the median time to positivity of blood cultures is still 15 hours (range, 2.6 to 127 hours), while the total time until full identification, including antimicrobial susceptibility, is often more than 72 hours for bacteria and more than 60 hours for fungi [22-24]. The time to positivity of blood cultures depends on the severity of the disease, the bacterial/fungal load, the type of pathogen and its growth capacity, polymicrobial infection, the volume of cultured blood, the system used for blood culturing, the time from sampling to incubation, and last but not least the presence of growth suppressants (for example, antibiotics) [22-24]. Thus, blood cultures are far from being an ideal gold standard as results are often delayed and incomplete and may not reflect all bacteriological evidence.

\section{Nucleic acid testing}

The application and assimilation of nucleic acid testing (NAT) for diagnosis of BSI have been hampered by recent improvements in culture-based methods and the disadvantage of representing add-on techniques that do not replace conventional blood cultures. Most of the NATs introduced within the past 20 years have been complex technologies with too small platforms, and are often poorly standardized tests developed in-house with limited impact on clinical decision-making. In addition, they may be more labour intensive and expensive and sometimes even less sensitive than culture-based approaches. The existing commercial NATs are, in general, based on a similar paradigm: pathogen lysis; nucleic acid extraction and purification; amplification of nucleic acids by PCR; and identification method (for example, ELISAbased hybridization, fluorescence-based real time detection, liquid or solid phase microarray detection, sequencing and database recognition).

In general, BSI assays either require prior cultivation steps and initiation from positive blood cultures or single colonies or are assays directly applicable to blood specimens. Irrespective of the need for prior cultivation, there are three main methodological approaches: single pathogen-specific assays that target species- or genusspecific genes (for example, PCR or other amplificationbased assays, hybridisation or fluorescence in situ hybridization); universal broad range assays targeting specific sequences in the bacterial or fungal genome (for example, panbacterial 16S, 5S, $23 \mathrm{~S}$ rDNA/RNA or panfungal 8S,18S, 5.8S, 28S rDNAs/RNAs) in blood followed by pathogen-specific identification; and multiplex PCR assays for parallel detection of species- or genus-specific targets of different pathogens. Tables 1 and 2 provide an overview of the most important, commercially available devices.

\section{Molecular identification of pathogens based on positive blood cultures}

Various culture-based NATs are currently commercially available. The most important limitation of these assays, however, is that they do not overcome the technical and sensitivity issues of blood cultures, cannot be directly applied to other biological specimens and are often only partially faster than non molecular-based technologies. Pathogen-specific assays are capable of detecting genes encoding resistance to antimicrobials, such as mecA in staphylococci or van genes in enterococci, allowing a faster phenotypic detection of resistance. These assays may have added value for antibiotic stewardship decisions by allowing the rapid de-escalation of empiric broadspectrum antibiotic treatment [25].

One such assay approved by the US Food and Drug Administration (FDA) is the GeneXpert system (Cepheid, Sunnyvale, CA, USA), which combines sample preparation and detection with real-time PCR in a closed and compact cartridge. GeneXpert detects methicillin 







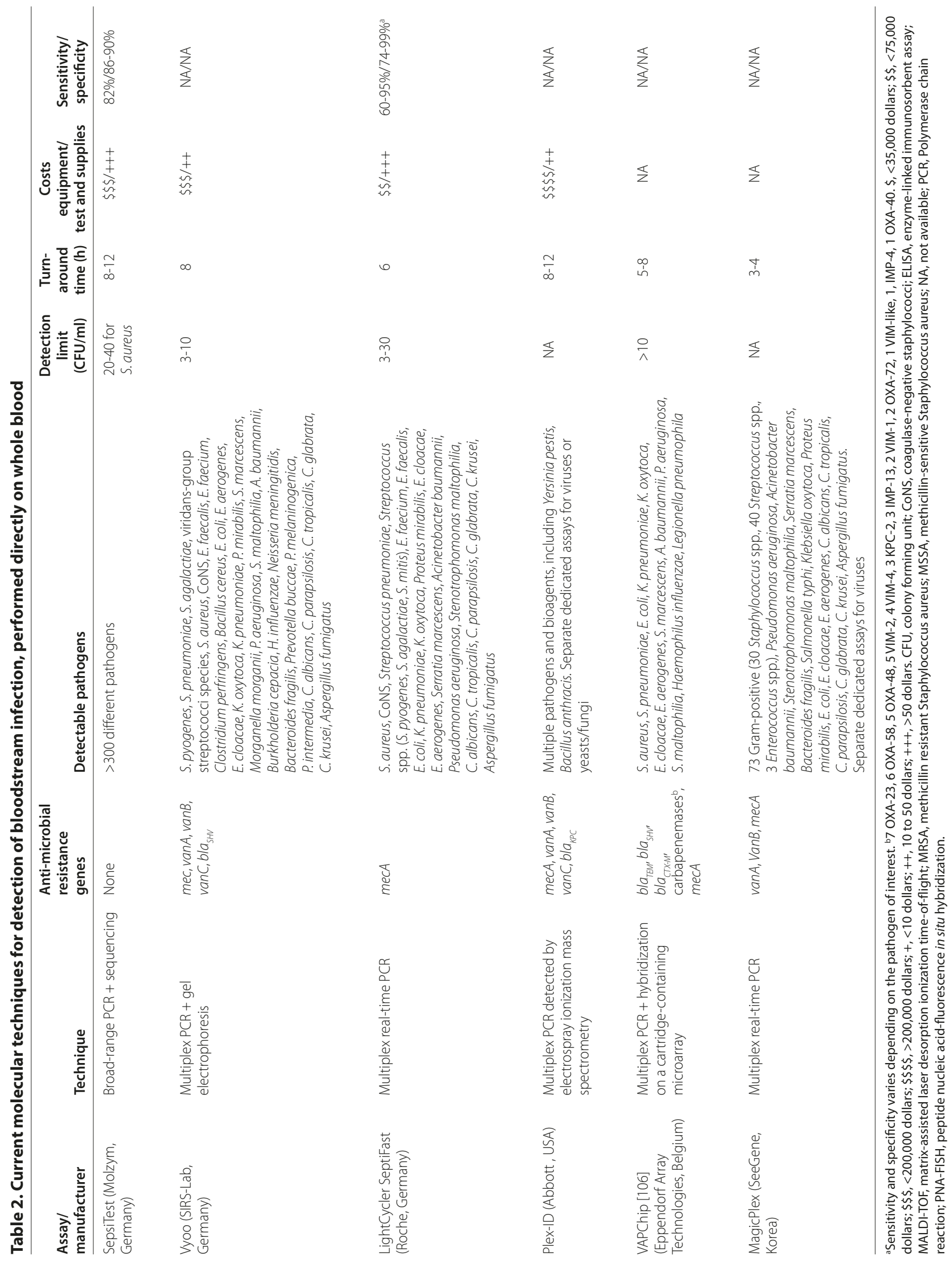


resistance or susceptibility (MRSA/MSSA) based on sequences in staphylococcal protein A (spa), SCCmec and $m e c A$ genes and has a turnaround time of 1 hour. It has a reported sensitivity of $100 \%$ and a specificity of $98.6 \%$ for Staphylococcus aureus detection and $98.3 \%$ and $99.4 \%$ for MRSA detection, respectively [26-28]. However, there is a small risk of false positives when testing for the SCCmec gene in the presence of methicillin-resistant, coagulasenegative Staphylococcus (CoNS) spp.

Another recently FDA-approved assay capable of identifying MRSA/MSSA within 5 hours based on evaluation of mecA and nuc genes is the KeyPath system (MicroPhage, Longmont, CO, USA) [29]. Another FDAapproved assay is StaphSR (BD GeneOhm, La Jolla, CA, USA), which runs on the SmartCycler instrument and amplifies specific target sequences of $S$. aureus for rapid detection of MSSA/MRSA with a turnaround time of 2.5 hours. For MRSA, the sensitivity, specificity, and positive and negative predictive values are reported to be $95.9 \%, 85.3 \%, 58.5 \%$, and $99.0 \%$, respectively [30,31]. However, other studies have shown discrepant results from this assay due to the presence of borderline MRSA strains [32,33].

Broad-range assays require an initial PCR amplification of a target sequence followed by several further identification strategies, such as sequencing, fragment size analysis or hybridization. Alternatively, the analysis of polymorphism or subsequent genus or species identification can be performed by real-time PCR assays. They target conserved sequences of bacterial and fungal genes such as those encoding ribosomal DNA.

Prove-it Sepsis (Mobidiag, Helsinki, Finland) is one of the first commercially available microarray-based molecular multiplex assays for sepsis detection in blood cultures. It combines broad-range PCR with amplification of gyrB, ParE and mecA genes. It uses the Prove-it ${ }^{\mathrm{TM}}$ StripArray system, which is compatible with its tubearray platform, and has a larger detection panel for both Gram-positive and Gram-negative bacteria than other existing culture-based NAT methods (24 species, 24 taxons, $m e c A$ for MRSA) with a turnaround time of 3 hours and a reported sensitivity of $95 \%$ and specificity of $99 \%$ for the pathogens included in its panel. It covers around $90 \%$ of all sepsis-causing pathogens, including fungi, but is a labour- and expertise-demanding approach [34].

BlackLight (BlackBio, Madrid, Spain) is a recent broadrange assay that identifies various bacteria by covering three regions of the $16 \mathrm{~S}$ ribosomal gene with a turnaround time of 4 hours. BlackLight detects Candida spp., Aspergillus fumigatus and Aspergillus niger and more than 400 fungal and yeast sequences based on the $18 \mathrm{~S}$ rRNA. It is a multistep approach based on pre-amplification reactions, including gelified PCR, three simultaneously conducted amplification reactions, three-step pyrosequencing and final identification by comparison with an existing database [35]. Clinical validation is still pending.

Multiplex assays with real-time PCR target different genes of pathogens identified from blood cultures in a single reaction but do not allow a direct application to blood samples. Hyplex BloodScreen (BAG, Lich, Germany) is a multiplex PCR assay that is able to detect several bacterial species via hybridisation in an ELISA-like format. It has a turnaround time of 3 to 4 hours, sensitivity $>96 \%$ and specificity $>92 \%$ and detects various resistance markers such as mecA, van and several $\beta$ lactamase genes [36,37].

StaphPlex (Qiagen, Valencia, CA, USA) is a culturebased multiplex PCR designed to identify $S$. aureus and several CoNS with various corresponding antimicrobial resistance determinants by combining the amplification of multiple targets (Biotin label) followed by hybridisation of the biotinylated PCR products on specific colourcoded capture probes with the Luminex xMAP technology [38,39]. The turnaround time is around 5 hours, with sensitivities ranging between $72.5 \%$ and $100 \%$ depending on the staphylococcal species identified.

The Nanosphere Verigene BC-GP system (Nanonsphere, Northbrook, IL, USA) is a recently CE-approved multiplex Gram-positive blood culture-based device capable of providing information on genus, species, and resistance detection of various pathogens within 2.5 hours on the same automated platform (Table 1) [40]. It provides information on resistance markers ( mecA, vanA and $v a n B$ ). A similar test for Gram-negative bacteria is expected to be launched soon. This platform still needs further clinical validation.

Beyond the scope of the amplification-based methods, peptide nucleic acid-fluorescence in situ hybridization (PNA-FISH; AdvanDx, Woburn, MA, USA) is an interesting alternative approach for antimicrobial stewardship. PNA probes, which are synthetic oligomers mimicking the DNA or RNA structure, allow the detection of microorganisms without the need for an amplification step and are thus less likely to be affected by contamination [40]. PNA-FISH enables targeting the rDNA of several Candida species and rRNA of a few bacteria. It does not require expensive infrastructure, is suitable for settings with lower resources, has a turnaround time of 2 to 3 hours and has an excellent sensitivity and specificity according to manufacturer-sponsored studies [41-46]. However, PNA-FISH has an insufficient detection panel for pathogens, is labour intensive, relies on previous Gram stain results and, most importantly, requires experienced and skilled technicians to interpret the results [42-44]. Furthermore, it requires active support from an antimicrobial stewardship team, otherwise there may be no added diagnostic value $[45,46]$. 
One of the greatest progresses in rapid detection of BSI-causing pathogens is related to protein-based identification via mass spectrometry (MS) techniques. Matrix-assisted laser desorption ionization time-of-flight (MALDI-TOF) MS (Bruker Daltonics, Bremen, Germany or BioMérieux, Marcy l'Etoile, France) performed on colonies obtained from culture-positive specimens, or even directly from aliquots of positive blood culture bottles, compares the mass spectral signals with a database of spectra from reference standard spectra. It is very swift (turnaround time of 1 to 2 hours), accurate (sensitivity 76 to $98 \%$ depending on the pathogen, specificity $>96 \%$ ) and reduces labour load. However, Gram-negative organisms appear to be much easier to detect than Gram-positives, with Streptococcus and Staphylococcus species and most commonly Streptococcus pneumoniae causing certain challenges [47-49]. It has a high device purchase cost (around 150,000 euros) but is rather inexpensive to use. However, MALDI-TOF MS does not reduce the required time for antibiotic resistance testing and still requires positive cultures. Furthermore, it fails to accurately identify polymicrobial infections due to dynamic range issues in the mass spectrometer and often detects only one pathogen of interest or may even cause false species identification [47-51].

\section{Direct pathogen identification by nucleic acid testing}

During the past 20 years, several PCR assays capable of direct detection of pathogens in blood and cerebrospinal fluid without prior cultivation have been introduced. Several automated platforms, either commercially available or under development, have the aim of direct detection of bacteria or fungi in blood components. Similar to culture-based methods, NAT assays can be divided between pathogen/genus-specific, broad-range and multiplex assays.

Several pathogen-specific assays have been developed for specific molecular targets and performed on specimens such as EDTA blood samples, serum, cardiac valves and vascular biopsy specimens [15,52-54]. They may be useful in cases of patients with a history of culturenegative infections caused by fastidious or slow-growing microorganisms. Genus-specific assays detect only a group of pathogens without detailed identification of the species, for instance, invasive aspergillosis in bronchoalveolar lavage fluid [55].

Broad-range assays potentially allow direct detection of cultivable and non-cultivable pathogens. The existing methods combine universal PCR, targeting conserved regions with sequencing, hybridisation or electrospray ionisation (ESI) MS. SeptiTest (Molzym, Bremen, Germany) is the only commercially approved broad-range PCR assay developed for diagnosis of BSI directly on blood without previous culturing. It targets $16 \mathrm{~S}$ rRNA genes of bacteria and the 18S rDNA of fungi and contains a fourstep approach (DNA extraction, PCR amplification, sequencing using primers, online-identification), which reduces issues caused by the presence of human DNA in an extracted specimen [56-58]. However, SeptiTest requires careful handling, is expensive, has a turnaround time of 5 to 12 hours and a high risk of false positives due to the multistep approach.

Multiplex real-time PCR assays and microarrays amplify multiple targets of DNA in the same biological sample simultaneously and is the most promising approach. However, the commercially available methods still lack sensitivity and a sufficiently broad panel of antibiotic resistance markers. The most commonly used device available since 2004, SeptiFast (Roche, Mannheim, Germany) is a real-time multiplex PCR-based assay available for sepsis diagnosis that can detect 25 clinically important bacteria and fungi directly from whole blood in about 6 hours [59-61]. SeptiFast is by far the most studied and validated assay and has a reported range of 60 to $95 \%$ sensitivity and 74 to $99 \%$ specificity depending on the target pathogen [59-72]. However, it is very labour-intensive, requires expertise to use, and has a high cost (150 to 200 euros per test). Moreover, except for MRSA, it provides no information on antimicrobial susceptibility. In a recent cohort study from Japan [73], it was shown that SeptiFast could complement traditional culture-based methods, particularly in antibiotic-treated patients.

VYOO (LOOXSTER, SIRS-Lab, Jena, Germany) is a multistep multiplex PCR (mechanical lysis and purification of DNA, human background DNA removal, PCR amplification of target DNA, amplicon gel electrophoresis and analysis) that can potentially detect 35 bacterial and 6 fungal species and important antimicrobial resistance detection, such as bla-SHV $\beta$-lactamase, mecA and vanA, $B$, and $C$ genes (vancomycin resistance) [57,74,75]. VYOO requires prior selective enrichment of microbial DNA (removal of human DNA) in a mixture with excess eukaryotic DNA by affinity chromatography, which may increase sensitivity to 3 to $10 \mathrm{CFU} / \mathrm{ml}$. The overall turnaround time is about 6 to 8 hours, but is not easy to use and has been clinically insufficiently validated.

PLEX-ID (Abbott Molecular, Carlsbad, CA, USA) is a recent multiplex real-time automated PCR with amplicon product detection by ESI MS [76,77]. PCR-ESI MS is designed to rapidly identify genotypic characterization of a broad range of bacteria, fungi, viruses and parasites in a given sample (for example, cultures or whole blood) via broad-range primers specific for groups of pathogens rather than for any one particular species [76,77]. Additional primer-pairs target identifiable genes for 
antibiotic resistance or particular pathogenic features $[78,79]$. PLEX-ID can identify more than one microorganism per sample, provides quantitative assessment of pathogen load, and detects drug resistance marker genes such as mecA, vanA, vanB and bla ${ }_{K P C}$ (carbapenem class in Klebsiella pneumoniae and other Gram-negative bacilli) [80-82]. A recent study indicates very good agreement between PCR-ESI MS and MALDITOF MS in detecting pathogens at the genus and species levels (0.94 to 0.97$)$ [83]. It is currently not available for clinical diagnostics due to the very high cost and undetermined sensitivity; clinical trials are pending.

MagicPlex (SeeGene, Seoul, Korea) is the most recent multiplex device with several platforms, including Magicplex Sepsis, which is able to detect more than 73 Gram-positive and 12 Gram-negative bacteria, 3 drug resistance markers (mecA, vanA and $v a n B$ ) and 6 fungi, covering over $90 \%$ of sepsis-related microorganisms. It is a multistep approach, where pathogen amplification is carried out by initially using the SelectNA ${ }^{\mathrm{TM}}$ blood pathogen kit, which extracts pathogen DNA from $1 \mathrm{ml}$ of whole-blood via an automated magnetic bead nucleic acid device (SEEPREP12 ${ }^{\mathrm{TM}}$ ). It is then followed by a pathogen amplification and detection process, combining conventional PCR (SEEAMP ${ }^{\mathrm{TM}}$ ) with real-time PCR (for example, CFX96 ${ }^{\mathrm{TM}}$, Bio-Rad; SmartCycler, Cepheid). It provides final information within 6 hours but has not yet been clinically validated [84].

\section{Limitation of nucleic acid testing}

The evaluation of NAT-based technologies for BSI diagnosis should encompass issues such as the range of detection, access to additional information such as antimicrobial susceptibility, turnaround time, throughput, technical complexity, time and effort required, as well as overall costs. More importantly, major issues to be addressed are differentiation of viable from non-viable microorganisms and the issue of microbial DNAaemia (DNA from live microorganisms versus DNA from dead microorganisms or free circulating DNA versus phagocytised DNA in immuno-competent host cells) as markers for an infectious focus somewhere in the host. The latter should be in the context of consideration and interpretation of the risk of potential contamination, as in the case of Gram-positive bacteria for blood cultures.

To date, the published clinical evaluation studies have suffered from serious shortcomings, such as the application of an inappropriate gold standard (blood cultures); emphasis on microbiological rather than clinical evaluation; no convincing cost-effectiveness analysis; no guidance for targeting appropriate clinical situations; and the potential for wrong interpretation of results if no expert assistance and advice are available. Thus, application of NAT in routine clinical practice requires more sophisticated infectious disease knowledge and guidance since the results may potentially complicate clinical decision making.

Pathogen-specific technologies often have specificity to one or a limited group of pathogens and may require add-on tests in order to exclude specific pathogens such as MRSA before enabling the clinician to narrow empiric antibiotic treatment. Broad-range NAT assays are better suited to detect pathogens identified by blood culture, but they are labour-intensive and costly, have low sensitivity and specificity due to the multi-step approach (risk of contamination), and save only marginal time compared to techniques such as MALDI-TOF MS when performed directly from positive blood cultures [85]. The risk of contamination refers not only to laboratory procedures during the PCR process (which has been dramatically reduced by closed systems) but also to contamination when obtaining the blood sample.

As new NATs are compared with blood cultures for diagnosis of BSI, a positive result for bacterial or fungal nucleic acids in the presence of negative culture poses interpretational challenges. It may reflect detection of pathogens due to a higher sensitivity of NAT for certain slow-growing or fastidious organisms. But NAT may also detect circulating nucleic acids, or non-proliferating, dead or degraded pathogens, which may be of clinical importance, for example, in antibiotic pre-treated patients in the ICU (for example, meningococcal sepsis). Finally, it may reflect contamination (for example, by CoNS) or carryover nucleic acid, especially after successful antimicrobial therapy, which may be detectable up to several days without apparent clinical significance $[86,87]$.

Despite the potentially high positive predictive value of the current NATs, the negative predictive value may be insufficient to exclude infection and the majority of the existing technologies are neither sensitive nor specific enough. Thus, more research is needed to improve the interpretation of circulating microbial nucleic acids (DNAaemia).

Finally, despite manufacturers' declared short turnaround times, clinicians often report a different experience when it comes to the availability of results. Under real-life conditions there are often considerable delays due to practical issues, such as specimen transportation and batch-wise analysis of samples, which reduce the intrinsic advantage of shorter turnaround times of the amplification-based tests, and availability of staff outside daily routines. In a recent study, for instance, the median time for availability of a SeptiFast result was between 18 and 27 hours [88], which contradicts recently reported potential cost and survival gains using SeptiFast for pathogen detection in sepsis [89]. 


\section{Criteria and challenges for improved point-of-care diagnostic tools for detection of BSI}

Development of the 'perfect' rapid diagnostic test for BSI hinges on two issues, sample preparation and detection. Sample preparation, including collection, lysis, extraction and enrichment of pathogen nucleic acid, is challenging since the microbial load in a sample can be as low as $0.1 \mathrm{CFU} / \mathrm{ml}$ in blood $[90,91]$. Thus, accurate diagnosis requires volumes of around $10 \mathrm{ml}$, but the nucleic acid loads of such volumes of blood will far exceed the purification capacity of current microfluid technologies as well as their overall volume capacity $(<1 \mathrm{ml})$ [92]. Bacteraemia in adults often presents with less than 10 $\mathrm{CFU} / \mathrm{ml}$ (range of 1 to $30 \mathrm{CFU} / \mathrm{ml}$ ), which is below the level of analytical sensitivity of many current PCR assays (3 to $100 \mathrm{CFU} / \mathrm{ml}$ ) [93].

A whole blood specimen contains human DNA located in circulating white blood cells, which will be co-isolated in great excess compared to pathogen nucleic acid and thus will decrease the sensitivity of pathogen detection [88]. Inadequate breakdown of distinct pathogens that are difficult to lyse and prepare adequately during nucleic acid extraction (for example, Gram-positive, yeasts, molds) is a further limitation [91,92]. Additionally, pathogens can, in certain cases, be adherent or sequestrated in blood cells and platelets, which may hamper the initial separation and extraction of pathogen nucleic acids [94].

As new NATs converge towards the principle of lab-onchip systems, most of the existing platforms are thus considered inadequate due to the requirement of preenrichment of the specimen, the reliance on prior cultivation in blood cultures and the limited antibiotic resistance testing. Although it is relatively simple to design strategies for single gene encoded resistance detection (for example, the mecA gene for methicillin resistance in S. aureus), this is not the case for many bacterial resistance types based on several distinct point mutations, such as penicillin resistance in pneumococci, and for more than 300 extended-spectrum $\beta$-lactamases among Gram-negative species [91,95].

Additionally, phenotypic resistance is influenced by different regulatory genes that play an important role in the expression of genes determining antimicrobial resistance. In the case of Gram-negative bacteria, the resistance genes are constantly evolving, making it costly and technically challenging to integrate the clinically most important genes into the existing or future NAT platforms. This reduces the negative predictive value of such assays, which is crucial in the clinical decision-making process, since clinicians need very high negative predictive values (ideally $>98 \%$ ) in order not to overuse broad spectrum antimicrobials such as carbapenems or not systematically add colistin, tigecyline or amikacin in settings with hyperendemic carbapenemase-producing bacteria.
Future assays require fully automated strategies applicable to various specimens that are also capable of quantifying the pathogen load as either a marker for disease severity (for example, S. pneumoniae) or in order to distinguish contamination (for example, CoNS) [96]. They should ideally provide relevant information 2 to 6 hours after specimens are taken in order to have an impact on the choice of treatment. They also need to improve the limited analytical sensitivity for clinically relevant low bacterial loads and for detection of certain bacteria and fungi that are difficult to detect, to distinguish between living and dead bacteria, to evaluate the role of transient bacteriaemia/fungaemia when no clinically apparent signs of infection are present, and finally to evaluate the impact of DNAaemia (DNA footprint) in cases of clinical signs of BSI.

\section{Conclusion}

Direct detection and identification of pathogens in blood or other specimens for rapid diagnosis of BSI by molecular approaches is a promising idea since it will facilitate early appropriate pathogen-driven therapy [97]. Despite substantial technological advances in the past decade, there is still a need for automated selective enrichment procedures for bacterial and fungal nucleic acids, blocking or elimination methods to eliminate excess human DNA, and use of viability markers to identify clinically relevant findings $[22,91]$. The target population most likely to benefit from the introduction of the rapid BSI diagnosis includes children (higher bacterial loads) [98] and patients with a high risk for infections with slow-growing, non-cultivable or intracellular bacteria or fungi, for example, neutropenic, transplant, critically ill and particularly antibiotic-pretreated patients.

An adequately validated NAT may ultimately influence trial design and facilitate the introduction of new antimicrobials by enabling more feasible comparative clinical trials (selected pathogens such as extended-spectrum $\beta$ lactamase producers, smaller sample size, substantial decrease in overall cost) and potentially assist in the introduction of new drugs.

The number of commercial PCR platforms for detection of pathogens is rapidly increasing but the lack of methodological and scientific rigor in the clinical examination and approval of emerging medical devices and failures in regulatory oversight before widespread clinical use, particularly in Europe [99,100], are worrisome. There is a lack of transparency in publishing research findings, device-related complications, adverse outcomes, and competing interests, since no formal and specific requirements for clinical evaluation trials of new molecular BSI test systems have been provided despite the introduction of The Standards for Reporting Diagnostic Accuracy $[99,100]$ and studies suggesting that new diagnostic tests 
should be more rigorously evaluated to establish their added value for clinical decision-making [101]. This stands in contrast to the many regulatory hurdles that companies face before introducing new antimicrobial compounds onto the market. Furthermore, the clinical and regulatory assessment of molecular BSI diagnosis systems should require a different reference approach based on clinical, radiological and bacteriological data, since blood cultures remain an imperfect gold standard due to inadequacy of blood cultures to detect many true cases of infection.

Currently, no available molecular method is, by itself, sufficiently accurate or sensitive enough to replace methods based on blood culture. Additionally, they tend to be more expensive and time-consuming to a degree which disqualifies them from being truly rapid diagnostics and thus limits them to certain expert labs.

Nevertheless, there is some evidence to support the add-on value of existing NATs as an adjunct to current culture methods in facilitating not only the early detection of more microorganisms (true positives) and important resistance genes (for example, $m e c A$ ) but also in reducing the time to optimal antimicrobial therapy and subsequent improved endpoints, such as reduced mortality, length of stay in hospital, overall costs and the use of broad-spectrum antibiotics [27,28,43,44, $72,89,102]$. Direct detection of pathogenic nucleic acids without prior cultivation despite diverging results from culture-based methods together with possible information on resistance markers may have significant added value in enabling evidence-based antibiotic stewardship, as detection of nucleic acid may indeed reflect the true clinical picture in specific clinical situations [103].

Continuous advances in whole-genome sequencing methods have the potential to enable parallel sequencing of pathogen specimens with various antimicrobial resistance elements. This will potentially guide treatment based solely on molecular measurements and subsequently eliminate the need for culture methods. However, this requires further improvements in areas such as interpretation of results (because of the inevitable increase in the detection of inconsequential nucleic acids from transient shedding and dead organisms), data management, verification and validation of sequence databases, cost of instrumentation and user friendliness.

A realistic, pragmatic and near-term solution that could potentially improve antibiotic stewardship would be the development of a rapid real-time nucleic acid point-ofcare test that detects few but clinically relevant pathogens (P. aeruginosa, A. baumanii, S. aureus, Klebsiella spp., E. coli and Candida spp.) and resistance genes (KPC, NDM, OXA 48, mecA, vanA and vanB). Ultimately, rapid molecular BSI diagnostics have the potential to become an essential tool for antibiotic stewardship in ICUs.

\section{Abbreviations}

BSI, bloodstream infection; CFU, colony-forming unit; CoNS, coagulasenegative staphylococci; ELISA, enzyme-linked immunosorbent assay; ESI, electrospray ionization; FDA, Food and Drug Administration; MALDITOF MS, matrix-assisted laser desorption ionization time-of-flight; MRSA, methicillin-resistant Staphylococcus aureus; MS, mass spectrometry; MSSA methicillin-sensitive Staphylococcus aureus; NAT, nucleic acid test/testing; PCR, polymerase chain reaction; PNA, peptide nucleic acid; PNA-FISH, peptide nucleic acid-fluorescence in situ hybridization.

\section{Competing interests}

SH has received consultant and speaker honoraria from bioMérieux (Marcy I'Etoile, France), Da Volterra (Paris, France), and Destiny Pharma (Brighton, UK). JS is Chief Medical Advisor for bioMérieux. AA and MI declare that they have no competing interests.

\section{Authors' statement}

All authors state that they have read and approved the manuscript. It has not been published nor is it under consideration for publication elsewhere.

\section{Acknowledgments}

Work by the authors was supported by the Innovative Medicines Initiative, a public-private partnership between the European Union and the European Federation of Pharmaceutical Industries and Associations (Rapp-ID grant agreement, no. 115153).

\section{Author details}

IInfection Control Program, Geneva University Hospitals and Medical School, 4, rue Gabrielle-Perret-Gentil, CH-1211 Geneva 14, Switzerland. 'Department of Anaesthesia, Juliane Marie Centre, Copenhagen University Hospital, Rigshospitalet, Copenhagen, Blegdamsvej 9, 2100, Denmark. ${ }^{3} \mathrm{Clinical}$ Microbiology Laboratory, Geneva University Hospitals and Medical School, Geneva, Switzerland. ${ }^{4}$ University of Antwerp, Vaccine and Infectious Diseases Institute, Laboratory of Medical Microbiology, University Hospital Antwerp, Wilrijkstraat 10 2650, Antwerp, Belgium.

Published: 29 May 2012

\section{References}

1. Melamed A, Sorvillo FJ: The burden of sepsis-associated mortality in the United States from 1999 to 2005: an analysis of multiplecause-of-death data. Crit Care 2009, 13:R28.

2. Engel $\mathrm{C}$, Brunkhorst FM, Bone HG, Brunkhorst R, Gerlach $\mathrm{H}$, Grond $\mathrm{S}$, Gruendling M, Huhle G, Jaschinski U, John S, Mayer K, Oppert M, Olthoff D, Quintel M, Ragaller M, Rossaint R, Stuber F, Weiler N, Welte T, Bogatsch H, Hartog C, Loeffler M, Reinhart K: Epidemiology of sepsis in Germany: results from a national prospective multicenter study. Intensive Care Med 2007, 33:606-618.

3. Harbarth S, Garbino J, Pugin J, Romand J, Lew D, Pittet D: Inappropriate initial antimicrobial therapy and its effect on survival in a clinical trial of immunomodulating therapy for severe sepsis. Am J Med 2003, 115:529-535.

4. Kumar A, Ellis P, Arabi Y, Roberts D, Light B, Parrillo JE, Dodek P, Wood G, Kumar A, Simon D, Peters C, Ahsan M, Chateau D; Cooperative Antimicrobial Therapy of Septic Shock Database Research Group: Initiation of inappropriate antimicrobial therapy results in a fivefold reduction of survival in human septic shock. Chest 2009, 136:1237-1248.

5. Carlet J, Collignon P. Goldmann D, Goossens H, Gyssens IC, Harbarth S, Jarlier V, Levy SB, N'Doye B, Pittet D, Richtmann R, Seto WH, van der Meer JW, Voss A. Society's failure to protect a precious resource: antibiotics. Lancet 2011, 378:369-371.

6. Binder U, Lass-Flörl C: Epidemiology of invasive fungal infections in the mediterranean area. Mediterr J Hematol Infect Dis 2011, 3:e20110016.

7. Miceli MH, Lee SA: Emerging moulds: epidemiological trends and antifungal resistance. Mycoses 2011, 54:e666-678.

8. Bassetti M, Ginocchio F, Giacobbe DR: New approaches for empiric therapy in Gram-positive sepsis. Minerva Anestesiol 2011, 77:821-827.

9. Spapen H, Jacobs R, Van Gorp V, Troubleyn J, Honoré PM: Renal and neurological side effects of colistin in critically ill patients. Ann Intensive Care 2011, 1:14.

10. Kane-Gill SL, Jacobi J, Rothschild JM: Adverse drug events in intensive care units: risk factors, impact, and the role of team care. Crit Care Med 2010, 
38:\$83-89.

11. Vallés J, Rello J, Ochagavía A, Garnacho J, Alcalá MA: Community-acquired bloodstream infection in critically ill adult patients: impact of shock and inappropriate antibiotic therapy on survival. Chest 2003, 123:1615-1624.

12. Garnacho-Montero J, Ortiz-Leyba C, Herrera-Melero I, Aldabó-Pallás T, Cayuela-Dominguez A, Marquez-Vacaro JA, Carbajal-Guerrero J, GarciaGarmendia JL: Mortality and morbidity attributable to inadequate empirical antimicrobial therapy in patients admitted to the ICU with sepsis: a matched cohort study. J Antimicrob Chemother 2008, 61:436-441.

13. Juan-Torres A, Harbarth S: Prevention of primary bacteraemia. Int J Antimicrob Agents 2007, Suppl 1:S80-87.

14. Seifert $\mathrm{H}$ : The clinical importance of microbiological findings in the diagnosis and management of bloodstream infections. Clin Infect Dis 2009, 48:S238-S245.

15. Mancini N, Carletti S, Ghidoli N, Cichero P, Burioni R, Clementi M: The era of molecular and other non-culture-based methods in diagnosis of sepsis. Clin Microbiol Rev 2010, 23:235-251.

16. Fenollar F, Raoult D: Molecular diagnosis of bloodstream infections caused by non-cultivable bacteria. Int J Antimicrob Agents 2007, 30:S7-S15.

17. Raad I, Hanna H, Maki D: Intravascular catheter-related infections: advances in diagnosis, prevention, and management. Lancet Infect Dis 2007, 7:645-657.

18. Lamas CC, Eykyn SJ: Blood culture negative endocarditis: analysis of 63 cases presenting over 25 years. Heart 2003, 89:258-262

19. Lee A, Mirrett S, Reller LB, Weinstein MP: Detection of bloodstream infections in adults: how many blood cultures are needed? J Clin Microbiol 2007, 45:3546-3548

20. Connell TG, Rele M, Cowley D, Buttery JP, Curtis N: How reliable is a negative blood culture result? Volume of blood submitted for culture in routine practice in a children's hospital. Pediatrics 2007, 119:891-896.

21. Yagupsky P, Nolte FS: Quantitative aspects of septicemia. Clin Microbio/ Rev 1990, 3:269-279

22. Leggieri N, Rida A, François P, Schrenzel J: Molecular diagnosis of bloodstream infections: planning to (physically) reach the bedside. Curr Opin Infect Dis 2010, 23:311-319.

23. Shah SS, Downes KJ, Elliott MR, Bell LM, McGowan KL, Metlay JP: How long does it take to "rule out" bacteremia in children with central venous catheters? Pediatrics 2008, 121:135-141.

24. Peralta G, Rodriguez-Lera MJ, Garrido JC, Ansorena L, Roiz MP: Time to positivity in blood cultures of adults with Streptococcus pneumoniae bacteremia. BMC Infect Dis 2006, 6:79

25. Okeke IN, Peeling RW, Goossens H, Auckenthaler R, Olmsted SS, de Lavison JF, Zimmer BL, Perkins MD, Nordqvist K: Diagnostics as essential tools for containing antibacterial resistance. Drug Resist Updat 2011, 14:95-106.

26. Wolk DM, Struelens MJ, Pancholi P, Davis T, Della-Latta P, Fuller D, Picton E, Dickenson R, Denis O, Johnson D, Chapin K: Rapid detection of Staphylococcus aureus and methicillin-resistant S. aureus (MRSA) in wound specimens and blood cultures: multicenter preclinical evaluation of the Cepheid Xpert MRSA/SA skin and soft tissue and blood culture assays. J Clin Microbiol 2009, 47:823-826

27. Bauer KA, West JE, Balada-Llasat JM, Pancholi P, Stevenson KB, Goff DA: An antimicrobial stewardship program's impact with rapid polymerase chain reaction methicillin-resistant Staphylococcus aureus/S. aureus blood culture test in patients with S. aureus bacteremia. Clin Infect Dis 2010, 51:1074-1080.

28. Parta M, Goebel M, Thomas J, Matloobi M, Stager C, Musher DM: Impact of an assay that enables rapid determination of Staphylococcus species and their drug susceptibility on the treatment of patients with positive blood culture results. Infect Control Hosp Epidemiol 2010, 31:1043-1048.

29. Costa AM, Kay I, Palladino S: Rapid detection of mecA and nuc genes in staphylococci by real-time multiplex polymerase chain reaction. Diagn Microbiol Infect Dis 2005, 51:13-17.

30. Stamper PD, Cai M, Howard T, Speser S, Carroll KC: Clinical validation of the molecular BD GeneOhm StaphSR assay for direct detection of Staphylococcus aureus and methicillin-resistant Staphylococcus aureus in positive blood cultures. J Clin Microbio/ 2007, 45:2191-2196.

31. Ho TH, Huang YC, Lin TY: Evaluation of the BD GeneOhm StaphSR assay for detection of Staphylococcus aureus in patients in intensive care units. J Microbiol Immunol Infect 2011, 44:310-315.

32. Gröbner S, Dion M, Plante M, Kempf VA: Evaluation of the BD GeneOhm StaphSR assay for detection of methicillin-resistant and methicillin-susceptible Staphylococcus aureus isolates from spiked positive blood culture bottles. J Clin Microbiol 2009, 47:1689-1694.

33. Snyder JW, Munier GK, Heckman SA, Camp P, Overman TL: Failure of the BD GeneOhm StaphSR assay for direct detection of methicillin-resistant and methicillin-susceptible Staphylococcus aureus isolates in positive blood cultures collected in the United States. J Clin Microbio/ 2009, 47:3747-3748.

34. Tissari P, Zumla A, Tarkka E, Mero S, Savolainen L, Vaara M, Aittakorpi A, Laakso S, Lindfors M, Piiparinen H, Mäki M, Carder C, Huggett J, Gant V: Accurate and rapid identification of bacterial species from positive blood cultures with a DNA-based microarray platform: an observational study. Lancet 2010, 375:224-230

35. Alistair Ritchie, Pablo Castán: Aplicación de nuevas técnicas de microsecuenciación dirigida a la detección de bacterias mediante pyrosecuenciación. LifeScienceLab 2010, 1:2-3.

36. Wellinghausen N, Wirths B, Essig A, Wassill L: Evaluation of the Hyplex BloodScreen multiplex PCR-enzyme-linked immunosorbent assay system for direct identification of gram-positive cocci and gram-negative bacilli from positive blood cultures. J Clin Microbio/ 2004, 42:3147-3152.

37. Avlami A, Bekris S, Ganteris G, Kraniotaki E, Malamou-Lada E, Orfanidou M, Paniara O, Pantazatou A, Papagiannitsis CC, Platsouka E, Stefanou I, Tzelepi E, Vagiakou H, Miriagou V: Detection of metallo- $\beta$-lactamase genes in clinical specimens by a commercial multiplex PCR system. J Microbiol Methods 2010, 83:185-187.

38. Zhang K, MCClure JA, Elsayed S, Louie T, Conly JM: Novel multiplex PCR assay for simultaneous identification of community-associated methicillinresistant Staphylococcus aureus strains USA300 and USA400 and detection of mecA and Panton-Valentine leukocidin genes, with discrimination of Staphylococcus aureus from coagulase-negative staphylococci. J Clin Microbio/ 2008, 46:1118-1122.

39. Tang YW, Kilic A, Yang Q, McAllister SK, Li H, Miller RS, McCormac M, Tracy KD Stratton CW, Han J, Limbago B: StaphPlex system for rapid and simultaneous identification of antibiotic resistance determinants and Panton-Valentine leukocidin detection of staphylococci from positive blood cultures. J Clin Microbiol 2007, 45:1867-1873.

40. Buhan BW, Mackey T, Cahak C, Couillar H, Marla S, Raich T, Sauer L, Jannetto PJ, Ledeboer NA: Evaluation of the microarray-based sample-to-result Verigene BC-GP assay for rapid detection of Gram-positive bacteria and resistance determinants directly from positive blood cultures [http://m.core-apps.com/TriStar-ICAAC11/abstract/9bd9d4e89691ff5649b4f0 f841e4c862]

41. Forrest GN: PNA FISH: present and future impact on patient management Expert Rev Mol Diagn 2007, 7:231-236.

42. Peleg AY, Tilahun Y, Fiandaca MJ, D’Agata EM, Venkataraman L, Moellering RC $\mathrm{Jr}$, Eliopoulos GM: Utility of peptide nucleic acid fluorescence in situ hybridization for rapid detection of Acinetobacter spp. and Pseudomonas aeruginosa. J Clin Microbiol 2009, 47:830-832.

43. Forrest Forrest GN, Roghmann MC, Toombs LS, Johnson JK, Weekes E, Lincalis DP, Venezia RA: Peptide nucleic acid fluorescent in situ hybridization for hospital-acquired enterococcal bacteremia: delivering earlier effective antimicrobial therapy. Antimicrob Agents Chemother 2008, 52:3558-3563.

44. Ly T, Gulia J, Pyrgos V, Waga M, Shoham S: Impact upon clinical outcomes of translation of PNA FISH-generated laboratory data from the clinical microbiology bench to bedside in real time. Ther Clin Risk Manag 2008 , 4:637-640

45. Holtzman C, Whitney D, Barlam T, Miller NS: Assessment of impact of peptide nucleic acid fluorescence in situ hybridization for rapid identification of coagulase-negative staphylococci in the absence of antimicrobial stewardship intervention. J Clin Microbio/ 2011, 49:1581-1582.

46. Shepard JR, Addison RM, Alexander BD, Della-Latta P, Gherna M, Haase G, Hall G, Johnson JK, Merz WG, Peltroche-Llacsahuanga H, Stender H, Venezia RA, Wilson D, Procop GW, Wu F, Fiandaca MJ: Multicenter evaluation of the Candida albicans/Candida glabrata peptide nucleic acid fluorescent in situ hybridization method for simultaneous dual-color identification of C. albicans and C. glabrata directly from blood culture bottles. J Clin Microbiol 2008, 46:50-55.

47. La Scola B: Intact cell MALDI-TOF mass spectrometry-based approaches for the diagnosis of bloodstream infections. Expert Rev Mol Diagn 2011, 11:287-298.

48. Kok J, Thomas LC, Olma T, Chen SC, Iredell JR: Identification of bacteria in blood culture broths using matrix-assisted laser desorption-ionization Sepsityper ${ }^{\mathrm{TM}}$ and time of flight mass spectrometry. PLoS One 2011, 
6:e23285

49. Seng P, Rolain JM, Fournier PE, La Scola B, Drancourt M, Raoult D: MALDI-TOFmass spectrometry applications in clinical microbiology. Future Microbiol 2010, 5:1733-1754.

50. Drancourt M: Detection of microorganisms in blood specimens using matrix-assisted laser desorption ionization time-of-flight mass spectrometry: a review. Clin Microbiol Infect 2010, 16:1620-1625.

51. Cherkaoui A, Hibbs J, Emonet S, Tangomo M, Girard M, Francois P, Schrenzel J: Comparison of two matrix-assisted laser desorption ionization-time of flight mass spectrometry methods with conventional phenotypic identification for routine identification of bacteria to the species level. J Clin Microbiol 2010, 48:1169-1175.

52. Sanchez-Jimenez MM, Cardona-Castro N: Validation of a PCR for diagnosis of typhoid fever and salmonellosis by amplification of the hilA gene in clinical samples from Colombian patients. J Med Microbio/ 2004, 53:875-878.

53. Rebollo MJ, San Juan Garrido R, Folgueira D, Palenque E, Díaz-Pedroche C, Lumbreras C, Aguado JM: Blood and urine samples as useful sources for the direct detection of tuberculosis by polymerase chain reaction. Diagn Microbiol Infect Dis 2006, 56:141-146.

54. Peters RP, van Agtmael MA, Gierveld S, Danner SA, Groeneveld AB, Vandenbroucke-Grauls CM, Savelkoul PH: Quantitative detection of Staphylococcus aureus and Enterococcus faecalis DNA in blood to diagnose bacteremia in patients in the intensive care unit. J Clin Microbiol 2007, 45:3641-3646.

55. Klingspor L, Loeffler J: Aspergillus PCR formidable challenges and progress. Med Mycol 2009, 47:S241-S247.

56. Mühl H, Kochem AJ, Disqué C, Sakka SG: Activity and DNA contamination of commercial polymerase chain reaction reagents for the universal $16 \mathrm{~S}$ rDNA real-time polymerase chain reaction detection of bacterial pathogens in blood. Diagn Microbiol Infect Dis 2010, 66:41-49.

57. Wellinghausen N, Kochem AJ, Disqué C, Mühl H, Gebert S, Winter J, Matten J, Sakka SG: Diagnosis of bacteremia in whole-blood samples by use of a commercial universal 16S rRNA gene-based PCR and sequence analysis. J Clin Microbiol 2009, 47:2759-2765.

58. Gebert S, Siegel D, Wellinghausen N: Rapid detection of pathogens in blood culture bottles by real-time PCR in conjunction with the pre-analytic tool MolYsis. J Infect 2008, 57:307-316.

59. Mencacci A, Leli C, Cardaccia A, Montagna P, Moretti A, Bietolini C, Meucci M, Perito S, Cenci E, Bistoni F: Comparison of conventional culture with SeptiFast real-time PCR for microbial pathogen detection in clinical specimens other than blood. J Med Microbiol 2011, 60:1774-1778.

60. Sancho-Tello S, Bravo D, Borrás R, Costa E, Muñoz-Cobo B, Navarro D: Performance of the LightCycler SeptiFast test Mgrade in detecting microbial pathogens in purulent fluids. J Clin Microbio/ 2011, 49:2988-2991.

61. Fernández AL, Varela E, Martínez L, Martínez A, Sierra J, González-Juanatey JR, Regueiro B: Evaluation of a multiplex real-time PCR assay for detecting pathogens in cardiac valve tissue in patients with endocarditis. Rev Esp Cardiol 2010, 63:1205-1208.

62. Lehmann LE, Hunfeld KP, Emrich T, Haberhausen G, Wissing H, Hoeft A, Stüber F: A multiplex real-time PCR assay for rapid detection and differentiation of 25 bacterial and fungal pathogens from whole blood samples. Med Microbiol Immunol 2008, 197:313-324

63. Wallet F, Loïez C, Herwegh S, Courcol RJ: Usefulness of real-time PCR for the diagnosis of sepsis in ICU-acquired infections. Infect Disord Drug Targets 2011, 11:348-353.

64. Bravo D, Blanquer J, Tormo M, Aguilar G, Borrás R, Solano C, Clari MA, Costa E, Muñoz-Cobo B, Argüeso M, Pineda JR, Navarro D: Diagnostic accuracy and potential clinical value of the LightCycler SeptiFast assay in the management of bloodstream infections occurring in neutropenic and critically ill patients. Int J Infect Dis 2011, 15:e326-331.

65. Josefson P, Strålin K, Ohlin A, Ennefors T, Dragsten B, Andersson L, Fredlund H, Mölling P, Olcén P: Evaluation of a commercial multiplex PCR test (SeptiFast) in the etiological diagnosis of community-onset bloodstream infections. Eur J Clin Microbiol Infect Dis 2011, 30:1127-1134.

66. Lehmann LE, Hauser S, Malinka T, Klaschik S, Weber SU, Schewe JC, Stüber F, Book M: Rapid qualitative urinary tract infection pathogen identification by SeptiFast real-time PCR. PLoS One 2011, 6:e17146.

67. Figueroa JR, Ortiz J, Morales I: Use of the LightCycler SeptiFast test for rapid etiologic diagnosis of nosocomial infection in gynecological sepsis. Gynecol Obstet Invest 2010, 70:215-216.

68. Maubon D, Hamidfar-Roy R, Courby S, Vesin A, Maurin M, Pavese P, Ravanel N,
Bulabois CE, Brion JP, Pelloux H, Timsit JF: Therapeutic impact and diagnostic performance of multiplex PCR in patients with malignancies and suspected sepsis. J Infect 2010, 61:335-342.

69. Avolio M, Diamante P, Zamparo S, Modolo ML, Grosso S, Zigante P, Tosoni N, De Rosa R, Stano P, Camporese A: Molecular identification of bloodstream pathogens in patients presenting to the emergency department with suspected sepsis. Shock 2010, 34:27-30.

70. Paolucci M, Capretti MG, Dal Monte P, Corvaglia L, Landini MP, Varani S, Pession A, Faldella G, Sambri V: Laboratory diagnosis of late-onset sepsis in newborns by multiplex real-time PCR. J Med Microbio/ 2009, 58:533-534.

71. Lucignano B, Ranno S, Liesenfeld O, Pizzorno B, Putignani L, Bernaschi P, Menichella D: Multiplex PCR allows rapid and accurate diagnosis of bloodstream infections in newborns and children with suspected sepsis. J Clin Microbiol 2011, 49:2252-2258.

72. Tsalik EL, Jones D, Nicholson B, Waring L, Liesenfeld O, Park LP, Glickman SW, Caram LB, Langley RJ, van Velkinburgh JC, Cairns CB, Rivers EP, Otero RM, Kingsmore SF, Lalani T, Fowler VG, Woods CW: Multiplex PCR to diagnose bloodstream infections in patients admitted from the emergency department with sepsis. J Clin Microbiol 2010, 48:26-33.

73. Yanagihara K, Kitagawa Y, Tomonaga M, Tsukasaki K, Kohno S, Seki M, Sugimoto H, Shimazu T, Tasaki O, Matsushima A, Ikeda Y, Okamoto S, Aikawa N, Hori S, Obara H, Ishizaka A, Hasegawa N, Takeda J, Kamihira S, Sugahara K, Asari S, Murata M, Kobayashi Y, Ginba H, Sumiyama Y, Kitajima M: Evaluation of pathogen detection from clinical samples by real-time polymerase chain reaction using a sepsis pathogen DNA detection kit. Crit Care 2010, 14:R159.

74. Sachse S, Straube E, Lehmann M, Bauer M, Russwurm S, Schmidt KH: Truncated human cytidylate-phosphate-deoxyguanylate-binding protein for improved nucleic acid amplification technique-based detection of bacterial species in human samples. J Clin Microbio/ 2009, 47:1050-1057.

75. Lehmann LE, Alvarez J, Hunfeld KP, Goglio A, Kost GJ, Louie RF, Raglio A, Regueiro BJ, Wissing H, Stüber F: Potential clinical utility of polymerase chain reaction in microbiological testing for sepsis. Crit Care Med 2009, 37:3085-3090

76. Kaleta EJ, Clark AE, Johnson DR, Gamage DC, Wysocki VH, Cherkaoui A, Schrenzel J, Wolk DM: Use of PCR coupled with electrospray ionization mass spectrometry for rapid identification of bacterial and yeast bloodstream pathogens from blood culture bottles. J Clin Microbiol 2011, 49:345-353.

77. Ecker DJ, Sampath R, Massire C, Blyn LB, Hall TA, Eshoo MW, Hofstadler SA: Ibis T5000: a universal biosensor approach for microbiology. Nat Rev Microbiol 2008, 6:553-558.

78. Hall TA, Sampath R, Blyn LB, Ranken R, Ivy C, Melton R, Matthews H, White N, Li F, Harpin V, Ecker DJ, McDougal LK, Limbago B, Ross T, Wolk DM, Wysocki V, Carroll KC: Rapid molecular genotyping and clonal complex assignment of Staphylococcus aureus isolates by PCR coupled to electrospray ionizationmass spectrometry. J Clin Microbiol 2009, 47:1733-1741.

79. Baldwin CD, Howe GB, Sampath R, Blyn LB, Matthews H, Harpin V, Hall TA, Drader JJ, Hofstadler SA, Eshoo MW, Rudnick K, Studarus K, Moore D, Abbott $S$, Janda JM, Whitehouse CA: Usefulness of multilocus polymerase chain reaction followed by electrospray ionization mass spectrometry to identify a diverse panel of bacterial isolates. Diagn Microbiol Infect Dis 2009, 63:403-408.

80. Ecker DJ, Sampath R, Li H, Massire C, Matthews HE, Toleno D, Hall TA, Blyn LB, Eshoo MW, Ranken R, Hofstadler SA, Tang YW: New technology for rapid molecular diagnosis of bloodstream infections. Expert Rev Mol Diagn 2010, 10:399-415

81. Sampath R, Hall TA, Massire C, Li F, Blyn LB, Eshoo MW, Hofstadler SA, Ecker DJ: Rapid identification of emerging infectious agents using PCR and electrospray ionization mass spectrometry. Ann N Y Acad Sci 2007, 1102:109-120

82. Eshoo MW Crowder CD, Li H, Matthews HE, Meng S, Sefers SE, Sampath R, Stratton CW, Blyn LB, Ecker DJ, Tang YW: Detection and identification of Ehrlichia species in blood using PCR and electrospray ionization mass spectrometry. J Clin Microbio/ 2010, 48:472-478.

83. Kaleta EJ, Clark AE, Cherkaoui A, Wysocki VH, Ingram EL, Schrenzel J, Wolk DM: Comparative analysis of PCR-electrospray ionization/mass spectrometry (MS) and MALDI-TOF/MS for the identification of bacteria and yeast from positive blood culture bottles. Clin Chem 2011, 57:1057-1067.

84. Seegene [http://seegene.com]

85. Bizzini A, Greub G: Matrix-assisted laser desorption ionization time-of-flight 
mass spectrometry, a revolution in clinical microbial identification. Clin Microbiol Infect 2010, 16:1614-1619.

86. Tomas I, Alvarez M, Limeres J, Potel C, Medina J, Diz P: Prevalence, duration and aetiology of bacteraemia following dental extractions. Oral Dis 2007 13:56-62.

87. Dark PM, Dean P, Warhurst G: Bench-to-bedside review: the promise of rapid infection diagnosis during sepsis using polymerase chain reactionbased pathogen detection. Crit Care 2009, 13:217.

88. Dierkes C, Ehrenstein B, Siebig S, Linde HJ, ReischI U, Salzberger B: Clinical impact of a commercially available multiplex PCR system for rapid detection of pathogens in patients with presumed sepsis. BMC Infect Dis 2009, 9:126

89. Lehmann LE, Herpichboehm B, Kost GJ, Kollef MH, Stüber F: Cost and mortality prediction using polymerase chain reaction pathogen detection in sepsis: evidence from three observational trials. Crit Care 2010, 14:R186.

90. Maaroufi Y, Ahariz N, Husson M, Crokaert F: Comparison of different methods of isolation of DNA of commonly encountered Candida species and its quantitation by using a real-time PCR-based assay. J Clin Microbiol 2004, 42:3159-3163

91. Dineva MA, MahiLum-Tapay L, Lee H: Sample preparation: a challenge in the development of point-of-care nucleic acid-based assays for resourcelimited settings. Analyst 2007, 132:1193-1199.

92. Klouche M, Schröder U: Rapid methods for diagnosis of bloodstream infections. Clin Chem Lab Med 2008, 46:888-908.

93. Peters RP, Mohammadi T, Vandenbroucke-Grauls CM, Danner SA, van Agtmael MA, Savelkoul PH: Detection of bacterial DNA in blood samples from febrile patients: underestimated infection or emerging contamination? FEMS Immunol Med Microbiol 2004, 42:249-253.

94. Kline KA, Fälker S, Dahlberg S, Normark S, Henriques-Normark B: Bacterial adhesins in host-microbe interactions. Cell Host Microbe 2009, 18:580-592.

95. Rubtsova MY, Ulyashova MM, Bachmann TT, Schmid RD, Egorov AM: Multiparametric determination of genes and their point mutations for identification of beta-lactamases. Biochemistry 2010, 75:1628-1649.

96. Rello J, Lisboa T, Lujan M, Gallego M, Kee C, Kay I, Lopez D, Waterer GW; DNA-Neumococo Study Group: Severity of pneumococcal pneumonia associated with genomic bacterial load. Chest 2009, 136:832-840.

97. Harbarth S, Nobre V, Pittet D: Does antibiotic selection impact patient outcome? Clin Infect Dis 2007, 44:87-93.
98. Horisberger T, Harbarth S, Nadal D, Baenziger O, Fischer JE: G-CSF and IL-8 for early diagnosis of sepsis in neonates and critically ill children - safety and cost effectiveness of a new laboratory prediction model. Study protocol of a randomized controlled trial. Crit Care 2004, 8:R443-450.

99. Cohen D, Billingsley M: Europeans are left to their own devices. BMJ 2011, 342:d2748.

100. Wilmshurst $P$ : The regulation of medical devices. BMJ 2011, 342:d2822.

101. Fischer J, Harbarth S, Agthe A, Benn A, Ringer S, Goldmann D, Fanconi S: Quantifying uncertainty: physicians' estimates of infection in critically ill neonates and children. Clin Infect Dis 2004, 38:1383-1390

102. Forrest GN, Mehta S, Weekes E, Lincalis DP, Johnson JK, Venezia RA: Impact of rapid in situ hybridization testing on coagulase-negative staphylococci positive blood cultures. J Antimicrob Chemother 2006, 58:154-158.

103. Westh H, Lisby G, Breysse F, Böddinghaus B, Chomarat M, Gant V, Goglio A, Raglio A, Schuster H, Stuber F, Wissing H, Hoeft A: Multiplex real-time PCR and blood culture for identification of bloodstream pathogens in patients with suspected sepsis. Clin Microbiol Infect 2009, 15:544-551.

104. Lindholm L, Sarkkinen H: Direct identification of gram-positive cocci from routine blood cultures by using AccuProbe tests. J Clin Microbiol 2004, 42:5609-5613.

105. Arbique JC, Poyart C, Trieu-Cuot P, Quesne G, Carvalho Mda G, Steigerwalt AG, Morey RE, Jackson D, Davidson RJ, Facklam RR: Accuracy of phenotypic and genotypic testing for identification of Streptococcus pneumoniae and description of Streptococcus pseudopneumoniae sp. nov. J Clin Microbiol 2004, 42:4686-4696.

106. Bogaerts $P$, de Mendonça R, Huang TD, Markine-Goriaynoff N, de Longueville F, Roisin S, Plüster W, Denis O, Glupczynski Y: Validation of a novel high multiplexing real-time PCR array for the identification and characterization of bacteria causative of ventilator-associated pneumonia [http://m.core-apps.com/TriStar-ICAAC11/abstract/ 9bd9d4e89691ff5649b4f0f841e6c73a]

doi:10.1186/cc11202

Cite this article as: Afshari A, et al:: Bench-to-bedside review: Rapid molecular diagnostics for bloodstream infection - a new frontier? Critical Care 2012, 16:222. 